\title{
Retenção do fungicida triadimenol em latossolos em razão da calagem e da fosfatagem
}

\author{
Júlio César Azevedo Nóbrega(1), José Maria de Lima ${ }^{(1)}$, Mário César Guerreiro(2), Renê Luís de Oliveira Rigitano(3) \\ e Sayonara Andrade do Couto Moreno ${ }^{(1)}$
}

(1)Universidade Federal de Lavras (Ufla), Dep. de Ciência do Solo, Caixa Postal 37, CEP 37200-000 Lavras, MG. E-mail: julionobrega@ufla.br, jmlima@ufla.br, sayocm@zipmail.com.br (2)Ufla, Dep. de Química. E-mail: guerrero@ufla.br (3)Ufla, Dep. de Entomologia. E-mail: rigitano@ufla.br

\begin{abstract}
Resumo - O objetivo deste trabalho foi avaliar o efeito da calagem e da fosfatagem na retenção do triadimenol em um Latossolo Vermelho-Amarelo distrófico (LVAd) e em um Latossolo Vermelho distrófico (LVd) em microcolunas de solo. Calagem e fosfatagem, realizadas em conjunto, reduziram a retenção do produto nas amostras do LVAd (7,7\% e 8,6\%, respectivamente, para a dose de 2,67 e 10,68 $\mathrm{kg} \mathrm{ha}^{-1}$ do princípio ativo). No LVd, a calagem e fosfatagem, quando realizadas isoladamente, causaram menor retenção do produto (calagem 7,2\% e 3,9\%, fosfatagem 10,1\% e 6,8\%, respectivamente, para as doses de 2,67 e 10,68 kg ha-1) em relação às amostras controle. Apesar da quantidade do produto na solução do solo ser inferior a $1 \%$ da dose aplicada, valores mais elevados do produto foram encontrados nas amostras de solo tratadas com calcário e fosfato, isoladamente ou não, no LVAd e, isoladamente, no LVd.
\end{abstract}

Termos para indexação: fertilidade do solo, sorção de pesticida, contaminação do solo.

\section{Retention of the fungicide triadimenol in Latosol due to lime and phosphate applications}

\begin{abstract}
The objective of this work was to evaluate the effect of liming and phosphate applications on the retention of triadimenol in microcolumns of soil material of a distrophic Red-Yellow Latosol (Typic Hapludox) and a distrophic Red Latosol (Typic Hapludox). Lime and phosphate applications decreased retention of triadimenol on LVAd samples (7.7\% and 8.6\%, respectively, for 2.67 and $10.68 \mathrm{~kg} \mathrm{ha}^{-1}$ of the active principle). Lower retention of triadimenol was observed on LVd samples when lime and phosphate were applied separately (liming 7.2\% and $3.9 \%$, phosphate fertilization $10.1 \%$ and $6.8 \%$, respectively, for 2.67 and $10.68 \mathrm{~kg} \mathrm{ha}^{-1}$ of the compound). In spite of the amount of the chemical in soil solution being inferior to $1 \%$ of the dose applied, higher values of the chemical were found in the samples with lime and phosphate, singly or not in the LVAd and singly in the LVd.
\end{abstract}

Index terms: soil fertility, pesticide sorption, soil contamination.

\section{Introdução}

As moléculas de pesticidas podem ser absorvidas pelas plantas e outros organismos do solo, transformadas por meios bióticos e abióticos, retidas pelos colóides orgânicos e inorgânicos do solo ou podem ser transportadas para outros compartimentos do ambiente.

A retenção é considerada um processo-chave no comportamento dessas moléculas no solo (Moraes \& Rezende, 1998), pois, dependendo da energia, do mecanismo e da extensão com que esse processo ocorre, a molécula dificilmente voltará à solução do solo (Lavorenti et al., 2003). Portanto, a retenção determina a quantidade de pesticida a ser aplicada, a fração que pode sofrer degradação ou absorção e o potencial de contaminação de outros compartimentos do ecossistema (Prata, 2002). Quando a molécula retida é transportada na água de enxurrada, ela tende a contaminar os ecossistemas aquáticos superficiais (Brown et al., 1995) e, quando transportada na água que percola através do perfil do solo, pode contaminar os ecossistemas aquáticos subsuperficiais (Kolpin et al., 1998). Trata-se, portanto, de um processo fundamental tanto na eficiência agronômica como no potencial de risco que tais substâncias podem representar ao ambiente (Prata, 2002).

Entre os pesticidas usados na agricultura brasileira, o triadimenol tem sido amplamente aplicado nas culturas do café, cana-de-açúcar, centeio, cevada, fumo, hortaliças, trigo, plantas ornamentais e outras (Clive, 1995). É um fungicida sistêmico, não-iônico, pertencente ao grupo dos triazóis, aplicado principalmente via solo no controle de diversas doenças causadas por fungos fitopatogênicos. No Brasil é usado no controle da ferrugem-do-café, doença causada pelo fungo Hemileia 
vastatrix Berk \& Br. (Gravena et al., 1993), responsável por grandes perdas de produção.

A molécula desse pesticida é sorvida principalmente na fração orgânica do solo (Gao et al., 1998; Lopes, 1999), o que tem sido atribuído à alta lipofilicidade do composto, $K_{d}$ entre 3,1 e 3,5, além de ser altamente persistente em solos, com valores de meia-vida entre 169 e 294 dias (Carvalho, 2000).

Uma vez que a interação do triadimenol se dá principalmente com a fração orgânica do solo (Gao et al., 1998), espera-se que qualquer fator ou prática de manejo que altere o comportamento dessa fração possa, direta ou indiretamente, influenciar a retenção do produto. Em solos mais intemperizados de regiões tropicais, há necessidade de correção e fertilização para reduzir a acidez e aumentar a disponibilidade de nutrientes às plantas. Neste caso, as práticas de calagem e fosfatagem são essenciais e exercem efeito sobre alguns atributos físico-químicos do solo (Albuquerque et al., 2003). Efeitos da calagem na dispersão de partículas, ponto de efeito salino nulo e potencial elétrico superficial (Albuquerque et al., 2003) além da fosfatagem na dispersão de partículas (Lima et al., 2000; Silva et al., 2001), balanço de cargas (Stumm, 1992; Lima et al., 2000), conteúdo de matéria orgânica (Myers \& Thien, 1991) e dissolução da matéria orgânica (Myers \& Thien, 1991; Jòzefaciuk et al., 1996; Gao et al., 1998) têm sido verificados.

O objetivo desse trabalho foi avaliar o efeito da calagem e da fosfatagem na retenção do triadimenol em um Latossolo Vermelho-Amarelo distrófico (LVAd) e em um Latossolo Vermelho distrófico (LVd) em microcolunas de solo.

\section{Material e Métodos}

Amostras de um Latossolo Vermelho-Amarelo distrófico (LVAd) e de um Latossolo Vermelho distrófico (LVd) foram coletadas $(0-20 \mathrm{~cm})$ em área sob vegetação nativa (floresta tropical subperenifólia) no campus da Universidade Federal de Lavras, Lavras, MG. A escolha desses solos justifica-se pelo fato de eles serem utilizados de forma intensa na cafeicultura da região.

Após a coleta, as amostras foram secadas ao ar, sendo uma fração de cada amostra passada em peneira de $4 \mathrm{~mm}$ para enchimento das colunas e outra fração passada em peneira de $2 \mathrm{~mm}$ para caracterização física e química. Na caracterização física do solo, foram determi- nadas a granulometria (Day, 1965) e estabilidade de agregados (Kemper \& Rosenau, 1986) (Tabela 1). Na caracterização química foram medidos os teores de cátions do complexo sortivo, $\mathrm{pH}$ em água, $\mathrm{P}$ disponível, C orgânico e óxidos $\left(\mathrm{Al}_{2} \mathrm{O}_{3}\right.$ e $\left.\mathrm{Fe}_{2} \mathrm{O}_{3}\right)$ extraídos pelo ataque sulfúrico (Embrapa, 1997). A capacidade máxima de adsorção de P (CMAP) foi determinada segundo Olsen \& Watanabe (1957) (Tabela 2).

Parte das amostras de solo destinadas ao enchimento das colunas foi incubada com $\mathrm{CaCO}_{3}$. A dose de calcário aplicada foi determinada pela curva de incubação para elevar o pH a 6,5. A dose definida de fosfato foi estabelecida como sendo metade do valor da CMAP (Tabela 2). O período de incubação foi de um mês, com umidade mantida em torno de $60 \%$ do volume total de poros. A seguir, metade das amostras que receberam calcário e metade das amostras sem calcário foram incubadas com fosfato $\left(\mathrm{KH}_{2} \mathrm{PO}_{4}\right)$ por mais um mês. A incubação resultou nas seguintes condições de amostras: controle (sem calcário e sem fosfato), com calcário, com fosfato e, com calcário e fosfato.

Após o período de incubação, $50 \mathrm{~g}$ de cada amostra foram colocados em microcolunas de aço inox com 3,5 cm de diâmetro interno e $6 \mathrm{~cm}$ de profundidade (densidade média do solo de $1,11 \mathrm{~g} \mathrm{~cm}^{-3}$ ). $\mathrm{O}$ delineamento experimental adotado foi o inteiramente casualizado, em esquema fatorial $2 \times 4$, correspondente a duas doses de triadimenol (250 e $1.000 \mu \mathrm{g}$ ) e quatro condições do solo: controle (sem calcário e sem fosfato); com calcário e sem fosfato; sem calcário e com fosfato e com calcário e fosfato, com três repetições, totalizando 24 parcelas experimentais para cada classe de solo. A dose $250 \mu \mathrm{g}$ consiste, quando se considera a superfície da microcoluna, numa aplicação de 2,67 kg ha-1 do princípio ativo.

Tabela 1. Caracterização física das amostras de Latossolo Vermelho-Amarelo distrófico (LVAd) e Latossolo Vermelho distrófico (LVd) da região de Lavras, MG.

\begin{tabular}{|c|c|c|c|c|c|c|}
\hline \multirow{2}{*}{\multicolumn{2}{|c|}{$\begin{array}{l}\text { Areia Silte } \\
-\mathrm{g} \mathrm{kg}^{-1}\end{array}$}} & \multirow{2}{*}{ Argila } & \multicolumn{4}{|c|}{ Diâmetro médio geométrico } \\
\hline & & & \multicolumn{4}{|c|}{ Controle Calcário Fosfato Calcário e fosfato } \\
\hline \multicolumn{7}{|c|}{ LVAd } \\
\hline 520 & 100 & 380 & 3,36 & 3,86 & 3,87 & 3,35 \\
\hline \multicolumn{7}{|c|}{$\mathrm{LVd}$} \\
\hline 240 & 70 & 690 & 4,24 & 4,12 & 3,97 & 3,55 \\
\hline
\end{tabular}


As amostras contidas nas colunas foram saturadas por capilaridade, com água destilada em recipientes individualizados antes da aplicação do produto. Em seguida, foi feita a aplicação de $1 \mathrm{~mL}$ de uma solução cetônica de triadimenol contendo $250 \mu \mathrm{g}$ ou $1.000 \mu \mathrm{g}$ do produto sobre a superfície do solo na coluna. As soluções usadas neste estudo foram preparadas a partir do padrão analítico de triadimenol com $97,4 \%$ de pureza.

Após uma hora da aplicação do produto, cada coluna foi submetida à centrifugação a $500 \mathrm{~g}$, por 10 minutos. Posteriormente, a base de cada coluna foi pesada para determinação da quantidade do extrato proveniente das colunas (efluente), o qual foi tratado para a avaliação da quantidade de triadimenol presente na solução. A amostra de solo contida na parte superior de cada coluna foi seccionada em camadas de $1 \mathrm{~cm}$ de espessura, totalizando quatro camadas $(0-1 ; 1-2 ; 2-3$ e 3-4 cm) por coluna para a extração do triadimenol retido no solo. O solo contido em cada camada foi pesado e uma amostra (cerca de $2 \mathrm{~g}$ ) foi levada para a estufa, a fim de determinar a quantidade de água retida em cada camada.

A avaliação do triadimenol na água proveniente das colunas foi feita conforme Allmendinger (1991), adaptada por Carvalho (2000). Assim, da amostra coletada em cada coluna, $10 \mathrm{~mL}$ foram transferidos para funil de separação de $125 \mathrm{~mL}$. Em seguida, foram adicionados $2 \mathrm{~mL}$ de solução saturada de $\mathrm{NaCl}$, visando atenuar e evitar a formação de emulsão durante a partição do composto, e $5 \mathrm{~mL}$ de diclorometano para extração do triadimenol da fase aquosa. A mistura foi agitada por um minuto e, posteriormente, a fase orgânica, contendo o triadimenol, foi recolhida em recipiente de vidro de $50 \mathrm{~mL}$. Esse procedimento de partição foi repetido por mais duas vezes, porém, sem a adição do cloreto de sódio. Para secar a fase orgânica, foi adicionado $1 \mathrm{~g}$ de $\mathrm{Na}_{2} \mathrm{SO}_{4}$ anidro e deixado em repouso por no mínimo 30 minutos e no máximo uma hora. Posteriormente, os sólidos, como $\mathrm{Na}_{2} \mathrm{SO}_{4}$, foram separados por filtração sob algodão. Em seguida, a amostra foi transferida para balão de fundo chato de $50 \mathrm{~mL}$ e secada em evaporador rotativo a $45^{\circ} \mathrm{C}$, sob vácuo. O resíduo de triadimenol foi recuperado com $2,5 \mathrm{~mL}$ de acetona e transferido para tubos de $5 \mathrm{~mL}$, utilizando-se pipeta de Pasteur e, posteriormente, encaminhado para análise por cromatografia em fase gasosa.

Testes de recuperação do triadimenol foram feitos em triplicata, por tratamento, a cada bateria de extração. Assim, $10 \mathrm{~mL}$ de cada amostra de água foram fortificados com $0,1 \mathrm{~mL}$ de solução $100 \mathrm{mg} \mathrm{L}^{-1}$. A concentração final obtida foi de $1 \mathrm{mg} \mathrm{L}^{-1}$. Após homogeneização da mistura, esta permaneceu em repouso por uma hora, antes de se iniciar o processo de extração do triadimenol. Os valores médios de recuperação do triadimenol nas amostras de água por tratamento foram: controle, 107,8\%; com calcário e sem fosfato, 105,9\%; sem calcário e com fosfato, 106,2\% e com calcário e fosfato, 102,8\%.

A extração do triadimenol retido nas amostras de solo foi realizada segundo Allmendinger (1991) e adaptada por Carvalho (2000). Nas amostras de solo coletadas em cada camada das colunas (cerca de $10 \mathrm{~g}$ de solo após correção para base seca), a extração do produto retido foi feita empregando-se $25 \mathrm{~mL}$ de solução extratora (acetona p.a. e água destilada na relação 3:1) em frascos de vidro de $100 \mathrm{~mL}$, sob agitação por uma hora em mesa agitadora, procedimento este repetido por mais uma vez. Após a segunda extração, as alíquotas foram reunidas e centrifugadas a $500 \mathrm{~g}$, por $10 \mathrm{minu}-$ tos. Uma alíquota de $20 \mathrm{~mL}$ do sobrenadante foi

Tabela 2. Caracterização química das amostras de Latossolo Vermelho-Amarelo distrófico (LVAd) e Latossolo Vermelho distrófico (LVd) da região de Lavras, $\mathrm{MG}^{(1)}$.

\begin{tabular}{|c|c|c|c|c|c|c|c|c|c|c|c|c|}
\hline \multirow[t]{2}{*}{$\mathrm{pH}^{(1)}$} & $\mathrm{Al}^{3+}$ & $\mathrm{Ca}^{2+}$ & $\mathrm{Mg}^{2+}$ & \multirow{2}{*}{\multicolumn{2}{|c|}{$\begin{array}{l}\mathrm{K}^{+} \\
\left(\mathrm{mg} \mathrm{dm}^{-3}\right)\end{array}$}} & \multirow{2}{*}{\multicolumn{3}{|c|}{$\frac{\text { LVAd }}{\text { LVA }}$}} & MO & $\mathrm{Al}_{2} \mathrm{O}_{3}$ & $\mathrm{Fe}_{2} \mathrm{O}_{3}$ & CMAP \\
\hline & & $\mathrm{mol}_{\mathrm{c}} \mathrm{dn}$ & ) ------- & & & & & & \multicolumn{4}{|c|}{--------------------- $\left(\mathrm{g} \mathrm{kg}^{-1}\right)$---------------------- } \\
\hline 5,0 & 1,0 & 0,2 & 0,1 & 33 & 1,0 & 0,4 & $\begin{array}{c}\text { LVA } \\
1,4 \\
\end{array}$ & 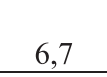 & 30 & 203,9 & 53,9 & 1.100 \\
\hline 4,9 & 0,9 & 0,2 & 0,1 & 20 & 1,0 & 0,4 & $\begin{array}{l}\mathrm{LVd} \\
1,3\end{array}$ & 10,2 & 41 & 319,1 & 171,8 & 2.000 \\
\hline
\end{tabular}

${ }^{(1)} \mathrm{pH}$ em água (1:2,5); P (Mehlich-1); S: bases trocáveis; t: capacidade de troca catiônica efetiva; T: capacidade de troca catiônica a pH 7,0; MO: matéria orgânica; CMAP: capacidade máxima de adsorção de fósforo. 
transferida para balão de fundo chato para se retirar o excesso de acetona em evaporador rotativo à temperatura do banho de $45^{\circ} \mathrm{C}$, sob vácuo. A seguir, a fase aquosa (aproximadamente $10 \mathrm{~mL}$ ) foi transferida para funil de separação de $125 \mathrm{~mL}$, sendo, nas fases seguintes da extração, empregado o mesmo procedimento analítico utilizado na extração do triadimenol da fase aquosa.

A eficiência do método analítico nas amostras de solo contendo os tratamentos foi feita em triplicata, fortificando-se $10 \mathrm{~g}$ de solo (TFSA) com $0,5 \mathrm{~mL}$ de solução $100 \mathrm{mg} \mathrm{L}^{-1}$. Após homogenização, a mistura permaneceu em repouso por 12 horas antes da extração do triadimenol. Os valores médios de recuperação do triadimenol nas amostras de solo, por tratamento, foram: controle, 107,9\%; com calcário e sem fosfato, 109,8\%; sem calcário e com fosfato, 108,8\% e com calcário e fosfato, $110,3 \%$.

Os extratos de triadimenol recuperados das amostras de solo e água foram analisados em um cromatógrafo gasoso Hewlett Packard - Série 6890, equipado com detector de captura de elétrons ( $\mu E C D)$. As condições de operação do aparelho foram: coluna HP-5 (30 m x $320 \mu \mathrm{m}$ x 0,25 $\mu \mathrm{m}$ com 5\% de fenil-metil siloxano). A temperatura do forno foi programada para iniciar a $100^{\circ} \mathrm{C}$ com duração de um minuto, rampa de aquecimento de $30^{\circ} \mathrm{C} \min ^{-1}$ até $280^{\circ} \mathrm{C}$, permanecendo dois minutos. As temperatura do injetor e detector foram de $250^{\circ} \mathrm{C}$ e $300^{\circ} \mathrm{C}$, respectivamente. $\mathrm{O}$ volume injetado foi 1,0 $\mu \mathrm{L}$ com modo de injeção "splitless", um minuto. O gás de arraste foi o $\mathrm{N}_{2}$ com fluxo de $1,5 \mathrm{~mL} \mathrm{~min}^{-1}$. Nessas condições analíticas, o tempo de retenção do triadimenol foi de 7 minutos e 14 segundos para o triadimenol A, e 7 minutos e 17 segundos para o triadimenol B. A concentração de triadimenol obtida em cada cromatograma corresponde ao somatório dos dois isômeros do composto. O padrão utilizado no preparo da curva padrão foi fornecido pela Bayer S.A., com pureza de $97,4 \%$.

Ao final do estudo foi realizado o balanço de massa do triadimenol. A diferença obtida entre a quantidade do produto inicialmente aplicada e aquela recuperada no solo e na solução do solo foi considerada como a fração dissipada da molécula (somatório das frações mineralizada, metabolizada e resíduo ligado).

Os dados obtidos foram submetidos à análise de variância e as médias entre os tratamentos foram com- paradas pelo teste de Scott-Knott, a 5\% e a 1\% de probabilidade.

\section{Resultados e Discussão}

O efeito das doses de triadimenol e práticas de manejo da fertilidade do solo na quantidade de triadimenol retido nas amostras do LVAd e LVd ocorreu de forma individual para as doses de triadimenol $(\mathrm{P}<0,01)$ e práticas de manejo da fertilidade $(\mathrm{P}<0,05)$ (Tabela 3 ). Nas amostras do LVAd, houve maior retenção do produto na dose de $1.000 \mu$ g, independentemente da condição inicial do solo. Amostras que receberam calcário e fosfato apresentaram menor retenção do produto. No LVd, foi observado o mesmo comportamento em relação às doses de triadimenol; no entanto, o efeito da calagem e da fosfatagem ocorreu de forma isolada. Em ambos os solos observou-se também que, embora maior sorção do produto tenha ocorrido com a aplicação da maior dose, a porcentagem retida em relação às doses aplicadas foi, independente da condição do solo, menor com a aplicação da maior dose. No LVAd a porcentagem retida entre os tratamentos foi em média de $94,9 \%$ e $90,8 \%$ e no $\mathrm{LVd}$ de $92,9 \%$ e $87,6 \%$, respectivamente, para as doses de 250 e $1.000 \mu \mathrm{g}$.

A redução na retenção do triadimenol pela calagem e fosfatagem no LVAd deve-se, possivelmente, à ação conjunta dessas práticas na alteração do comportamento eletroquímico dos colóides do solo, como conseqüência das modificações que promovem na composição química da solução do solo, pH, força iônica e outras. O aumento no pH do solo pela calagem (Roth et al., 1986; Roth \& Pavan, 1991) e fosfatagem (Myers \& Thien, 1991) contribui, entre outros aspectos, para aumentar a matéria orgânica dissolvida (Myers \& Thien, 1991; Jòzefaciuk et al., 1996; Gao et al., 1998), o que pode reduzir a retenção do triadimenol pelo solo, uma vez que a interação do produto à fase sólida do solo ocorre predominantemente por partição hidrofóbica na matéria orgânica do solo (Gao et al., 1998; Carvalho, 2000).

Jòzefaciuk et al. (1996) verificaram redução na área superficial e perda de sítios de alta energia de adsorção nas superfícies das partículas do solo, por causa da perda de matéria orgânica dissolvida em função da variação do pH. Esse efeito tem reflexo na redução da 
adsorção e, conseqüentemente, aumento da dessorção do triadimenol (Gao et al., 1998).

O efeito isolado do calcário e do fosfato no LVd reduzindo a retenção do triadimenol em relação ao LVAd deve-se a teores mais elevados de matéria orgânica do LVd (Tabela 2) que, provavelmente, em função das práticas de calagem e fosfatagem, propiciaram maior quantidade de matéria orgânica em solução e, conseqüentemente, diminuição na retenção do triadimenol.

A menor quantidade de triadimenol encontrada nos tratamentos com calagem e fosfatagem pode ter sido, também, decorrente da formação de resíduo ligado no processo de dissipação da molécula (Tabela 3), principalmente considerando-se o pouco tempo de condução do ensaio para ocorrência de processos de mineralização e degradação. Resíduo ligado, segundo Führ (1997), designa a interação de espécies químicas originadas da transformação ou não de pesticidas com uma matriz (solo, planta ou animal), não sendo estes resíduos passíveis de extração por métodos que não alterem significativamente a natureza da molécula e da matriz. Neste caso, dois esclarecimentos precisam ser feitos: i) que a fração extraída do produto, em ambos os solos, não representa na totalidade a fração sorvida, já que pequena parte dessa fração permanece como resíduo ligado e; ii) que o efeito da calagem e fosfatagem na redução da sorção do produto se dá sobre a fração extraível do triadimenol.

A importância da formação de resíduo ligado na dissipação de pesticidas foi levantada por Lavorenti et al. (2003) para o diclosulam, um herbicida pertencente ao grupo químico das triazolpirimidina sulfonanilidas e por Gamble et al. (2000) para o clorotalonil, um fungicida não-iônico de elevado coeficiente de partição octanol:água ( $\left.\log \mathrm{K}_{\mathrm{ow}}=2,88\right)$. Segundo Gamble et al. (2000), a cinética de formação de resíduo ligado desse produto ocorre em duas fases distintas: uma fase rápida (aproximadamente 24 horas), provavelmente determinada por processos de superfície, seguida de uma fase lenta, na qual a formação de resíduo ligado ocorre por difusão da molécula no interior de substâncias húmicas.

Em virtude de a fração dissipada de triadimenol ser decorrente unicamente da formação de resíduo ligado, este fato passa a ser importante na avaliação do comportamento sortivo do produto sob efeito das práticas de calagem e fosfatagem. A relevância dessa informação pode ser atribuída ao fato de que a fração de resíduo ligado de um pesticida tende a aumentar com o aumento do tempo de contato do produto com o solo

Tabela 3. Quantidade de triadimenol sorvida e na solução do solo em razão da aplicação de calcário e fosfato no Latossolo Vermelho-Amarelo distrófico (LVAd) e no Latossolo Vermelho distrófico (LVd) ${ }^{(1)}$.

\begin{tabular}{|c|c|c|c|c|}
\hline $\begin{array}{l}\text { Triadimenol } \\
\qquad(\mu \mathrm{g})\end{array}$ & Controle & Calcário & Fosfato & Calcário e fosfato \\
\hline \multicolumn{5}{|c|}{ LVAd - Sorção } \\
\hline 250 & $244,2 \mathrm{bA}$ & $237,6 \mathrm{bA}$ & $241,9 \mathrm{bA}$ & $225,0 \mathrm{bB}$ \\
\hline 1.000 & $919,9 \mathrm{aA}$ & $937,4 \mathrm{aA}$ & $943,1 \mathrm{aA}$ & $833,8 \mathrm{aB}$ \\
\hline \multicolumn{5}{|c|}{ LVd - Sorção } \\
\hline 250 & $242,1 \mathrm{bA}$ & $224,0 \mathrm{bB}$ & $216,8 \mathrm{bB}$ & $246,1 \mathrm{bA}$ \\
\hline 1.000 & $897,6 \mathrm{aA}$ & $860,6 \mathrm{aB}$ & $831,7 \mathrm{aB}$ & $910,0 \mathrm{aA}$ \\
\hline \multicolumn{5}{|c|}{ LVAd - Solução } \\
\hline 250 & $0,8 \mathrm{bB}$ & $1,7 \mathrm{bA}$ & $1,2 \mathrm{bA}$ & $2,8 \mathrm{bA}$ \\
\hline 1.000 & $2,6 \mathrm{aB}$ & $6,3 \mathrm{aA}$ & $5,4 \mathrm{aA}$ & $6,8 \mathrm{aA}$ \\
\hline \multicolumn{5}{|c|}{ LVd - Solução } \\
\hline 250 & $0,8 \mathrm{bB}$ & $1,4 \mathrm{bA}$ & $1,4 \mathrm{bA}$ & $0,5 \mathrm{bB}$ \\
\hline 1.000 & $2,8 \mathrm{aB}$ & $8,0 \mathrm{aA}$ & $4,4 \mathrm{aA}$ & $2,6 \mathrm{aB}$ \\
\hline \multicolumn{5}{|c|}{ LVAd - Dissipação } \\
\hline 250 & 5,0 & 10,7 & 6,9 & 22,2 \\
\hline 1.000 & 77,5 & 56,3 & 51,5 & 159,4 \\
\hline \multicolumn{5}{|c|}{ LVd - Dissipação } \\
\hline 250 & 7,1 & 24,6 & 31,8 & 3,4 \\
\hline 1.000 & 99,6 & 131,4 & 163,9 & 87,4 \\
\hline
\end{tabular}

${ }^{(1)}$ Médias seguidas pelas mesmas letras, minúsculas nas colunas e maiúsculas nas linhas, não diferem entre si, respectivamente, a 1\% e a 5\% de probabilidade, pelo teste de Scott-Knott; em relação à sorção o coeficiente de variação foi de 6,7\% (LVAd) e 6,1\% (LVd) e em relação à solução, de $18,1 \%$ (LVAd) e 19,2\% (LVd). 
(Gamble et al., 2000; Lavorenti et al., 2003). Esse comportamento pode promover um acúmulo do pesticida na superfície dos solos, uma vez que a dificuldade de transformação da molécula será bem maior do que daquelas que se encontram livres na solução do solo.

No LVd, as amostras que receberam calcário e fosfato também apresentaram maior retenção do produto, comparativamente àquelas que receberam calcário ou fosfato. Esse resultado pode ser atribuído ao forte efeito dispersivo dessas práticas neste solo, quando realizadas em conjunto, conforme verificado pelo menor diâmetro médio geométrico dos agregados (Tabela 1) devido ao aumento no potencial elétrico negativo superficial, mais pronunciado neste solo em face do maior teor de óxidos de ferro e alumínio (Tabela 2).

$\mathrm{O}$ aumento na dispersão do solo promoveu um aumento na quantidade de microporos que, provavelmente, contribuiu para elevar a retenção do triadimenol neste tratamento. Segundo Farrel \& Reinhard (1994), moléculas retidas em microporos possuem maior força de sorção em relação às sorvidas nos planos de superfície. Conforme os autores, isto ocorre pelo fato de os microporos apresentarem tamanho próximo ao da molécula sorvida, revelando uma energia de sorção aproximadamente cinco vezes maior que a do plano de superfície. Assim, dependendo dos atributos físico-químicos e mineralógicos do solo, as práticas de calagem e fosfatagem podem contribuir para reduzir a retenção do triadimenol nas amostras de solo, em conseqüência do aumento que promovem da matéria orgânica em solução, ou elevar a retenção do produto, por causa do aumento que promovem na quantidade de microporos.

A menor porcentagem retida de triadimenol com a aplicação da maior dose do produto em ambos os solos é atribuída ao efeito competitivo das moléculas pelos sítios ativos da matéria orgânica (disponíveis) para a retenção do produto. Ao estudar a cinética de sorção do triadimenol, Carvalho (2000) verificou que, uma hora após a aplicação do produto, praticamente se alcança o equilíbrio de sorção. Segundo o autor, isto revela que a sorção na superfície em que estão expostos os sítios mais imediatos para retenção do produto é um processo rápido.

As práticas de calagem e fosfatagem influenciaram o perfil de distribuição do produto ao longo das microcolunas (Figura 1). No LVAd o triadimenol, inici- almente aplicado à superfície, foi encontrado em todas as profundidades estudadas, principalmente nas amostras tratadas com calcário e fosfato, nas quais a menor retenção do produto na profundidade de $0-1 \mathrm{~cm}$ foi seguida de um aumento nas frações de maior profundidade. No LVd a distribuição do triadimenol em profundidade nas colunas, ocorreu, principalmente nas amostras tratadas com calcário e fosfato, isoladamente.

O efeito dos tratamentos na quantidade de triadimenol encontrada na solução mostrou também, em ambos os solos, efeitos individuais quanto às doses de triadimenol $(\mathrm{P}<0,01)$ e práticas de manejo da fertilidade do solo $(\mathrm{P}<0,05)$ (Tabela 3).

No LVAd, o triadimenol na solução do solo foi mais elevado na maior dose aplicada nas amostras que receberam calcário e fosfato, isoladamente ou em conjunto. No LVd, além do efeito da dose de triadimenol, foi verificado efeito isolado da calagem e da fosfatagem no aumento do triadimenol em solução. $\mathrm{O}$ aumento do triadimenol na solução do solo nos tratamentos que receberam calcário e fosfato no LVAd e, calcário e fosfato isoladamente no LVd, é decorrente da menor retenção do produto nas amostras de solo com esses tratamentos. No LVAd, embora a calagem e fosfatagem isoladamente tenham aumentado o triadimenol em solução, esse efeito não foi suficiente para causar diferenças significativas nestes tratamentos na quantidade retida na coluna (Tabela 3).

O efeito da calagem e fosfatagem, isoladamente ou em conjunto, no aumento do triadimenol em solução, deve-se, entre outros aspectos, ao fato de a interação do triadimenol com a fase sólida do solo ocorrer indiretamente por meio de grupamentos orgânicos. Neste caso, o aumento de dissolução da matéria orgânica da fase sólida do solo, direta ou indiretamente, contribuiu para uma menor retenção do triadimenol, conseqüentemente, elevando-se a quantidade do produto na solução do solo. Efeitos da calagem e fosfatagem na dissolução da matéria orgânica têm sido verificados por Myers \& Thien (1991), Jòzefaciuk et al. (1996) e Gao et al. (1998), com reflexo no aumento da dessorção do triadimenol (Gao et al., 1998).

Apesar dos efeitos das práticas de calagem e fosfatagem na elevação do produto em solução (Tabela 3), a quantidade recuperada do produto foi inferior a $1 \%$ das doses aplicadas, fato que mostra a elevada capacidade de sorção do produto nas amostras de solo. 


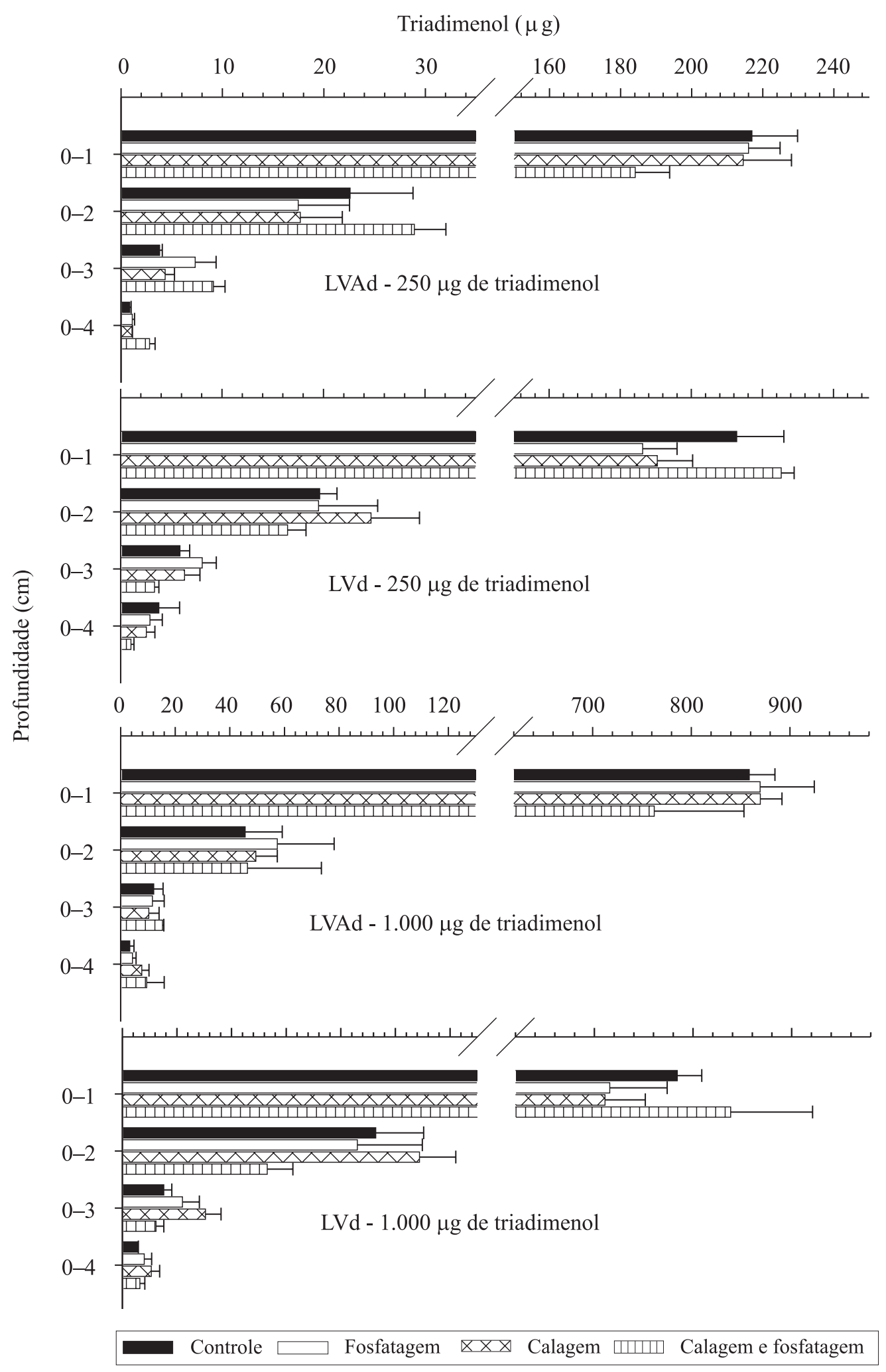

Figura 1. Distribuição do triadimenol em profundidade nas microcolunas de solo contendo amostras de um Latossolo Vermelho-Amarelo distrófico (LVAd) e Latossolo Vermelho distrófico (LVd), sob efeito da calagem e fosfatagem. Barras em cada coluna representam o desvio-padrão da média de três repetições. 


\section{Conclusões}

1. A calagem e a adubação fosfatada influenciam de forma diferenciada a retenção do triadimenol nas amostras do LVAd e LVd.

2. Menor retenção do triadimenol ocorre quando a calagem e a adubação fosfatada foram realizadas em conjunto no LVAd e isoladamente no LVd.

3. A calagem e a adubação fosfatada aumentam a quantidade de triadimenol em solução, quando realizadas de forma isolada ou em conjunto no LVAd e isoladamente no $\mathrm{LVd}$.

\section{Agradecimento}

Ao CNPq, pelas bolsas concedidas a Júlio César Azevedo Nóbrega, José Maria de Lima, Renê Luís de Oliveira Rigitano e Sayonara Andrade do Couto Moreno.

\section{Referências}

ALBUQUERQUE, J.A.; BAYER, C.; ERNANI, P.R.; MAFRA, A.L.; FONTANA, E.C. Aplicação de calcário e fósforo e estabilidade da estrutura de um solo ácido. Revista Brasileira de Ciência do Solo, v.27, p.799-806, 2003.

ALLMENDINGER, H. A method for determining residues of the fungicides Folicur, and Bayfidan in plant material and soil by gas chromatography. Pflanzenschutz Nachrichten Bayer, v.44, p.566, 1991.

BROWN, C.D.; HODGKINSON, R.A.; ROSE, D.A.; SYERS, J.K.; WILCOCKSON, S.J. Movement of pesticides to surface waters from a heavy clay soil. Pesticide Science, v.43, p.131140, 1995.

CARVALHO, R.F. Sorção e degradação do fungicida triadimenol em solos representativos do município de Lavras - MG. 2000. 54p. Dissertação (Mestrado) - Universidade Federal de Lavras, Lavras.

CLIVE, T. A world compendium the pesticide manual: incorporating the agrochemicals handbook. $10^{\text {th }}$ ed. Surrey, UK: Crop Protections Publications, 1995. 1341p.

DAY, P.R. Particle fractionation and particle-size analysis. In: BLACK, C.A. (Ed.). Methods of soil analysis. Madison: American Society of Agronomy, 1965. v.1, p.545-566.

EMBRAPA. Centro Nacional de Pesquisa de Solos (Rio de Janeiro, RJ). Manual de métodos de análises de solo. 2.ed. Rio de Janeiro: Embrapa-CNPS, 1997. 212p.

FARREL, J.; REINHARD, M. Desorption of halogenated organics from model solids, sediments, and soil under unsaturated conditions: 1- Isotherms. Environmental Science \& Technology, v.28, p.53-62, 1994.
FÜHR, F. Non-extractable pesticides residues in soil. In: GREENHALG, R.; ROBERTS, T.R. (Ed.). Pesticide Science and Biotechnology. Oxford: International Union of Pure and Applied Chemistry, 1987. p.381-389.

GAMBLE, D.S.; BRUCCOLERI, A.G.; LINDSAY, E.; LANGFORD, C.H.; LEYS, G.A. Chlorothalonil in a quartz sand soil: speciation and kinetics. Environmental Science Technology, v.34, p.20-124, 2000.

GAO, J.P.; MAGUHN, J.; SPITZAUER, P.; KETTRUP, A. Sorption of pesticides in the sediment of the Teufelsweiher pond (Southern Germany): 1- Equilibrium assessments, effect of organic carbon content and $\mathrm{pH}$. Water Research, v.32, p.16621672, 1998.

GRAVENA, S.; HARADA, S.S.; BENETOLI, I.; YAMAMOTO, P.T. Comparação de estratégias de manejo de pragas e doenças do cafeeiro (Coffea arabica L.), var. Mundo Novo, na região de Marília, SP. Científica, v.21, p.139-147, 1993.

JÒZEFACIUK, G.; SOKOLOWSKA, Z.; HAJNOS, M.; HOFFMANN, C.; RENGER, M. Large effect of leaching of DOC on water adsorption properties of a sandy soil. Geoderma, v.74, p.125-137, 1996.

KEMPER, W.D.; ROSENAU, R.C. Aggregate stability and size distribution. In: KLUTE, A. Methods of soil analysis: Part 1Physical and mineralogical methods. $2^{\text {nd }}$ ed. Madison: American Society of Agronomy, 1986. v.1, p.425-442. (Agronomy Monograph, 9).

KOLPIN, D.W.; BARBASH, J.E.; GILLION, R.J. Occurrence of pesticides in shallow groundwater of the United States: inicial results from the National Water-Quality Assessment Program. Environmental Science and Tecnology, v.32, p.558-566, 1998.

LAVORENTI, A.; ROCHA, A.A.; PRATA, F.; REGITANO, J.B.; TORNISIELO, V.L.; PINTO, O.B. Comportamento do diclosulam em amostras de um Latossolo Vermelho distroférrico sob plantio direto e convencional. Revista Brasileira de Ciência do Solo, v.27, p.183-190, 2003.

LIMA, J.M.; ANDERSON, S.J.; CURI, N. Phosphate-induced clay dispersion as related to aggregate size and composition in Hapludoxs. Soil Science Society of America Journal, v.64, p.892-897, 2000.

LOPES, N.P. Adsorção do triadimenol por frações de solo associadas a um composto de lixo urbano. 1999. 100p. Dissertação (Mestrado) - Universidade Federal de Viçosa, Viçosa.

MORAES, S.L.; REZENDE, M.O.O. Comportamento sortivo dos herbicidas s-triazinas em solo e em ácidos húmicos. Revista Ecotoxicologia e Meio Ambiente, v.8, p.157-170, 1998.

MYERS, R.; THIEN, S.J. Soil permeability in an ammonium and phosphorus application zone. Soil Science Society of America Journal, v.55, p.866-871, 1991.

OLSEN, S.R.; WATANABE, F.S. A method to determine a phosphorous adsorption maximum of soils as measured by the Langmuir isotherm. Soil Science Society of America Proceedings, v.21, p.144-149, 1957.

PRATA, F. Comportamento do glifosato no solo e deslocamento miscível de atrazina. 2002. 149p. Tese (Doutorado) - Universidade de São Paulo, Piracicaba. 
ROTH, C.M.; PAVAN, M.A. Effects of lime and gypsum on clay dispersion and infiltration in samples of a Brazilian Oxisol. Geoderma, v.48, p.351-361, 1991.

ROTH, C.M.; PAVAN, M.A.; CHAVES, J.C.D.; MEYER, B.; FREDE, H.G. Efeitos de aplicações de calcário e gesso sobre a estabilidade de agregados e infiltrabilidade de água em um latossolo roxo cultivado com cafeeiro. Revista Brasileira de Ciência do Solo, v.10, p.163-166, 1986.
SILVA, R.B.; LIMA, J.M.; DIAS JUNIOR, M.S.; SILVA, F.A.M. Influência da adição de fósforo no índice de compressão e parâmetros de consistência de um Latossolo Vermelho-Escuro. Revista Brasileira de Ciência do Solo, v.25, p.261-268, 2001.

STUMM, W. Chemistry of the solid-water interface: processes at the mineral-water and particle water interface in natural systems. New York: John Wiley, 1992. 428p.

Recebido em 13 de julho de 2004 e aprovado em 3 de dezembro de 2004 